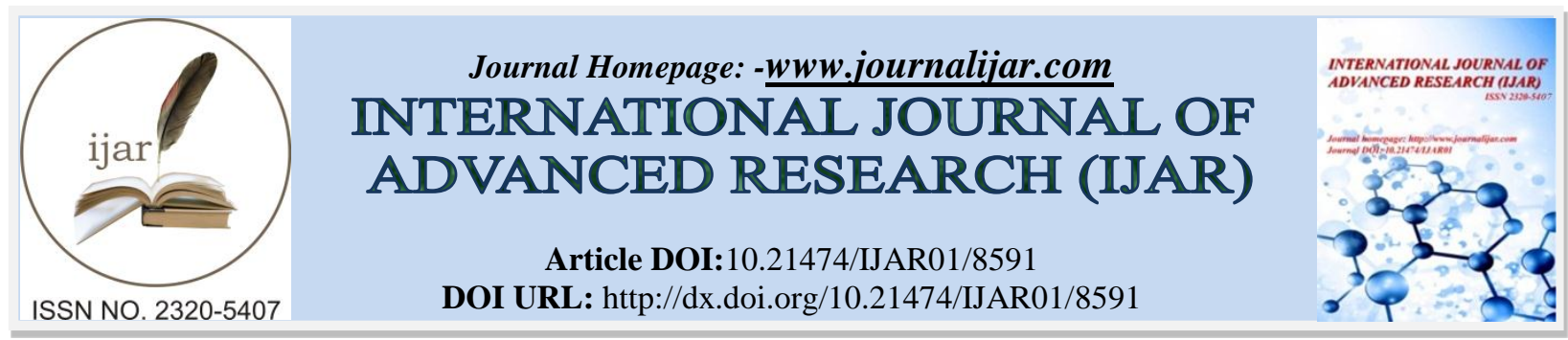

RESEARCH ARTICLE

\title{
ASSESSMENT OF CRISIS AND CONFLICT REGIONS IN RESPONSE OF HYBRID THREATS AND CONFLICTS.
}

Ivo Zahariev.

G. S. Rakovski National Defence College, 1504, Sofia, 82 Evlogi and Hristo Georgievi Bulgaria Blvd, Bulgaria.

\section{Manuscript Info}

Manuscript History

Received: 02 January 2018

Final Accepted: 04 February 2019

Published: March 2019

Key words:-

hybrid threats, assessment, crisis and

conflict regions, counteraction.

\section{Abstract}

The assessment of crisis and conflict areas is the basis for responding to hybrid threats for each country. Adequate assessment of crisis and conflict areas can lead to more effective counteraction of hostile, hybrid impact. Separate examples are given for some of the indicators.

The proposed mathematical model for assessing the complex impact of the environment in which operations against hybrid threats will be conducted will help to make adequate counter-solutions.

Copy Right, IJAR, 2019,. All rights reserved.

\section{Introduction:-}

Contemporary risks and threats to country security arise out of their territories as a result of the change in behavior, significance and interests of key global and regional players, stemming from the particular situation in crisis and conflict areas around the world.

The strategic assessment of the security environment shows that in many regions progressively deteriorates the situation, with the negative development of processes being conditioned by a set of factors that can be conditionally divided into internal and external.

Among the many threats related to the international security environment, in recent years, those of a hybrid type, i.e. of a complex nature, that act simultaneously are particularly relevant.

In particular, hybrid threats imply the use of different actions of varying nature for pressure on the opposing party. Among them, military action is only part of the instruments used, while at the same time increasing the role of nonmilitary means to achieve the objectives set. Many experts predict that hybrid threats to international security will increase in the near future.

Today, the "hybrid war" is the most advanced version and form of military conflict in which all the means and methods known to mankind to destroy the enemy, from the oldest primitive to the latest warfare technology, are used. Hybrid War is pre-planned at a strategic level, combined symmetrical and asymmetric actions, with extensive use of information and psychological operations.[6]

New forms of military action can be described as voluminous, encompassing all aspects of armed struggle (land, sea, air, space), where the electronic, power and information impacts will be carried out with increasing intensity in time and space to allow the provision results in the shortest possible time, depriving the enemy of initiative and the freedom to maneuver.

Corresponding Author:-Ivo Zahariev. 
The probability of causing internal state conflicts increases due to the exacerbation of globalization-related cultural conflicts, irrational and ineffective governance, and the widening of the environment in which destabilizing groups can operate.

Conflicts between state security structures on the one hand and non-state actors, mainly in the face of terrorist organizations and groups, are expected to increase in quantity and to sharpen as a counterweight. In this sense, as a result, the importance of the role of the armed forces in the fight against terrorism, both internal and external, is expected to increase, especially when it pursues the strategic effect of its actions.

Crisis and conflict areas in Europe, Africa and Asia have a place, and so on, hybrid conflicts (wars). In these cases, a complex of non-military measures - political, economic, informational, psychological, etc. - implemented through military action is used. In addition, there is no need to develop new weapons and combat systems, for example, for conducting a hybrid conflict (war) existing ones are sufficient.[5]

The main components of hybrid threats, which inherently pose individual threats:

1. Threats of a political and diplomatic nature;

2. Threats of informational nature;

3. Threats of a psychological nature;

4. Threats of cyber attacks;

5. Threats of an economic nature;

6. Threats of protest actions and destructive public actions;

7. Threats of force action;

8. Threats of large-scale refugees and migratory waves.

The combined and purposeful action of these components in different combinations in one space determines and forms the hybrid threats. In most hybrid threats, traditional elements (military or other force) and non-traditional elements (non-military character) are also present in different combinations.

Given the fact that hybrid threats are preceded by hybrid actions, the analysis of problems should be deepened in the direction of hybrid conflicts (wars) that have taken place in recent years.

The existence of crises and conflicts, changing the balance of power in the world, the significant number of frozen conflicts in different parts of the world call for the development and development of capabilities to use a modern approach to analyzing and assessing crisis or conflict areas to aid in taking of future decisions at the strategic level. At the same time, it is necessary to build capabilities for assessment and analysis of the environmental factors that will affect contemporary and future operations.[4]

Taking into account the specificities of modern operations predetermines the need to take into account the impact of many factors that influence the options for action in each country.

There are a number of factors affecting the conduct of operations, which can be divided into several areas according to their common signs of impact, the most important of which are:[3]

External factors - political environment, military environment, economic environment, social environment, information environment, geography of the area, infrastructure, protected areas and climatic conditions.

Internal factors - doctrinal documents on the use of the armed forces of the country; combat characteristics of the weapon, military equipment and intelligence means; level of training of all participants in the operation area; available resources for conducting combat operations; the state of leadership training and organizational culture; the moral-psychological status of the personnel from the formations, their readiness to perform combat tasks regardless of the difficulties, the manifestation of initiative, creativity, readiness for self-sacrifice, etc.

External factors should be analyzed as follows: political environment; military environment; economic environment; social environment; information environment; geography of the area, infrastructure, protected zones, climatic conditions. 
Internal factors should be assessed against the following:

1. doctrinal documents on the use of the armed forces of the country;

2. the combat characteristics of the weapon, the military equipment and the means of intelligence;

3. the level of training of all participants in the operation area;

4. available resources for conducting combat operations;

5. state of leadership and organizational culture;

6. moral-psychological status of the personnel from the formations, their readiness to perform combat tasks regardless of the difficulties, the manifestation of initiative, creativity, readiness for self-sacrifice, etc.

7. the nature of civilian-military relations.

External and internal factors are in symbiosis and have a complex impact on the conduct of operations and decisionmaking to counteract hybrid threats.

In order to determine their impact, it is necessary to systematize them on the basis of the signs of their manifestation and to determine how they act on the conduct of the operation. Their impact on the conduct of the operation may be beneficial, unfavorable or relatively favorable.

To determine their influence, we use the following mathematical apparatus. The estimation of each factor is measured by the cumulative batch method using a five-step scale.

For the purposes of the study, a mathematical model for the assessment of the environmental factors, separated as proposed in the classification above, was selected. A five-scale scale is selected in which the lowest category is 0.2. For each factor is calculated the amount of ball from its impact assessment by formula:[2]

$$
\text { Smil. env. }=\sum_{i=1}^{5} \quad S_{i}
$$

where $\mathrm{S}$ is the aggregate of the estimates of the factors;

$i$ - the number of signs of each factor;

S1 - military capabilities of the opposing;

S2 - friendly forces;

S3 - neighbors;

S4 - paramilitary formations;

S5 - neutral forces;

Accordingly, the influence formulas for each environment with their variables are given below. Because the assessment of the political environment is given in the guidelines at the strategic level for conducting the operation, they are not included in the calculation.

$$
\text { Secon.env. }=\sum_{i=1}^{5} \quad S_{i}
$$

where $\mathrm{S}$ is the aggregate of the estimates of the factors;

$\mathrm{i}$ - the number of signs of each factor;

S1 - production;

S2 - distribution of goods and services;

S3 - consumption of goods and services;

S4 - indications of internal voltage;

S5 - economic stability;

$$
\text { Ssocial env. }=\sum_{i=1}^{5} \quad S_{i}
$$

where $\mathrm{S}$ is the aggregate of the estimates of the factors;

$i$ - the number of signs of each factor;

S1 - demographic, degree of urbanization;

$\mathrm{S} 2$ - religion, literacy and degree of education;

$\mathrm{S} 3$ - migration trends;

S4 - standard of living; 
S5 - Cohesion and activities of cultural, religious or ethnic groups;

$$
\text { Sinf.env. }=\sum_{i=1}^{5} \quad S_{i}
$$

where $\mathrm{S}$ is the aggregate of the estimates of the factors;

$\mathrm{i}$ - the number of signs of each factor;

$\mathrm{S} 1$ - complete infrastructure;

S2 - organization;

S3 - components;

S4 - networks;

S5 - groups;

$$
\text { Sfactor }=\sum_{i=1}^{5} \quad S_{i}
$$

where $\mathrm{S}$ is the aggregate of the estimates of the factors;

$\mathrm{i}$ - the number of signs of each factor;

S1 - geography of the locality;

$\mathrm{S} 2$ - infrastructure;

$\mathrm{S} 3$ - protected areas;

S4 - climatic conditions;

S5 - others;

$$
\text { Sinternal factors }=\sum_{i=1}^{5} \quad S_{i}
$$

where $\mathrm{S}$ is the aggregate of the estimates of the factors;

$\mathrm{i}$ - the number of signs of each factor;

S1 - doctrinal base;

$\mathrm{S} 2$ - combat characteristics of the armament;

S3 - level of training for all participants in the operation area;

S4 - available resource for conducting combat operations;

S5 - state of leadership training and organizational culture, moral-psychological status of the personnel from the formations;

The assessment of the complex environment is calculated as the sum of all other environments to answer how it will affect the operation:

$$
\text { Scomplex env. }=\sum_{i=5}^{5} \quad S i
$$

where $\mathrm{S}$ is the aggregate of the estimates of the factors;

$i$ - the number of signs of each factor;

Smil.env. - military environment;

Secon.env. - economical sphere;

Sinf.env. - information environment;

Sfactors - geography, climate, etc .;

Sinternal factors - internal factors;

Experts judge each factor as to how it works (favorably or unfavorably) over the phases of the operation. The level of influence assessed for each factor can be based on the mission, the developed and analyzed action directions. A summary of a five-step scale for the level of influence is presented in the table. The letter in the title (title) for each degree (A through E) is the symbol to indicate the influence. For example, the letter "A" represents a "beneficial" level.

\begin{tabular}{|l|l|l|}
\hline \multicolumn{1}{|c|}{ Letter } & \multicolumn{1}{|c|}{ Degree of influence } & \multicolumn{1}{c|}{ Value } \\
\hline A & FAVORABLY & $0,8-1$ \\
\hline B & MORE FAVORABLE & $0,6-0,79$ \\
\hline C & RELATIVLY FAVORABLE & $0,4-0,59$ \\
\hline D & RELATIVLY URGENTLY & $0,2-0,39$ \\
\hline E & URGENTLY & $0-0,19$ \\
\hline
\end{tabular}


The current approach to assessing crisis and conflict areas is based on the theory and practice of conflict management and crisis management. In particular, for crises and conflicts of a military nature, a system of indicators covering a complete set of crisis and conflict processes and events - from their emergence to the consequences for a given country - can be used.

It can be based and presented through a system of indicators as follows:[7]

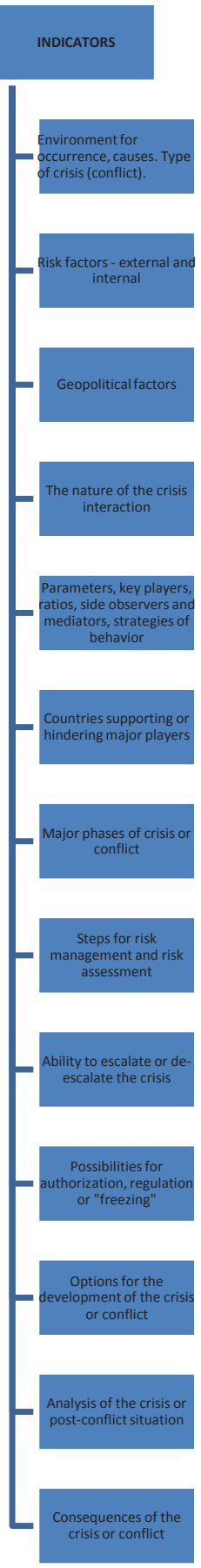

The assessment of the first indicator should assess the occurrence of the conflict, motivation reasons, objectives and participants in the crisis or conflict, as well as the resources used for the specific events. As a result, the type of crisis or conflict in the given area is formulated. 
The assessment of the second indicator defines the risk factors that have led to the crisis or conflict in the region. The risk factors are manifested as an imbalance in armaments and the state of the armed forces between neighboring countries or the consequences of large-scale natural disasters.

The third indicator evaluates the geopolitical factors associated with the crisis or conflict area. These factors are the territory of the country; its geographic location; raw materials and energy resources; infrastructure; numeracy, density and population structure; climate; relief; soils, etc. As you can see, some of the listed geopolitical factors change slowly, others are unchanged and their influence is stable and lasting.

For example, at the present time, the most important geopolitical factors associated with a conflict region such as Afghanistan are the key geographic location of the country in South Asia in terms of the interests of the Great Powers; opportunities to control production, distribution and illicit drug trafficking; the open problem with the development of the transport and energy corridors through Afghanistan to Pakistan and the gas pipelines of the Indian Ocean.

Another example is that the war in Syria directly affects international oil-gas flows. The Syrian Arab Republic is a natural transit territory of energy resources from Iraqi Kurdistan, the Arabian Peninsula and the Persian Gulf (Qatar, Yemen, Kuwait, UAE, Oman, Saudi Arabia, Iran, Iraq, Bahrain). Besides, Syria closes the coast, where there are huge gas reserves.

The fourth indicator evaluates the area of disagreement in the area where the crisis interaction or the conflict collision develops. The disclosure of the conflicting interests of the interacting states makes it possible to determine the nature of the crisis interaction or the conflict clash and the likely objectives.

The assessment of the fifth indicator should be the parameters of the conflict and the periods of development, key actors, side observers and mediators, behavior strategies, disagreement, micro and macro environment.

When assessing the sixth benchmark, countries evaluating or assisting or disrupting key players are assessed. Here we analyze the main interconnections between states and political alliances in which they participate to analyze the support that the different actors in the conflict would receive. Support can be both active and passive. For example, in the intra-Syrian conflict, the outside players quickly intervened, trying to make the most of the chaos in the country. Among the regional players in the Syrian armed conflict are Turkey, Iran, Israel, Lebanese Hezbollah, Gulf countries and Saudi Arabia, Qatar and the UAE.

The assessment of the seventh indicator assesses the current situation in which particular phase the crisis has experienced (the stage of conflict development) in the region and its characteristics. For example, the main phases of an escalating political crisis can be an exasperated social situation, a controlled public conflict, and uncontrollable public conflict, and the main stages of a possible military conflict are pre-conflict, open (visible) and post-conflict. When assessing the eighth indicator, the risk management theory is applied, the same being assessed for the particular crisis or conflict area. Most often, after identifying the hazards for each of the major threats, the opportunities for work in the crisis or conflict area are assessed at acceptable levels of risk.

In assessing the ninth indicator through conflict, the possibilities for escalation or de-escalation of the crisis or conflict in the region, as well as for their development in a regional or global crisis or conflict, are assessed.

From a military point of view, a military conflict in Syria with the participation of international forces can not be mastered, because in any case it will cover Iran as well. In this case, it is not possible to anticipate the consequences, as a possible intervention by Israel would be fully predictable, as a preventive action. There is no way to exclude the use of nuclear weapons in such decisive strikes. Such a development of the conflict could not be controlled not only by the United States, but also by NATO and even by the global democratic community. The extraordinary risk to global security, which lies in the current situation, is obvious. This scenario is reported by both the US and NATO and the Russian Federation. It is in the interest of all major geopolitical players not to reach this conclusion and this in turn gives reason to foresee that they will do everything possible to avoid the situation out of control. 
The assessment of the tenth benchmark assesses the possibilities for resolving, regulating or "freezing" the crisis or conflict in the region by using force and non-force means and measures. The pursuit of the international community is primarily the implementation of peaceful means, with diplomatic, political and economic measures taking the lead in this instrument.[1]

The assessment of the eleventh indicator identifies possible options for the development of the crisis or conflict. For example, as a result of the crisis analysis in Afghanistan, four possible scenarios of peace and conflict are emerging: the preservation of the status quo, a functioning decentralized state, a functioning centralized state, and regional redistribution.

Another example of the situation in Syria. There are four options - rebels will also gain Syria to become a radical Islamist state, such as Qatar, S. Arabia. Bad option, but unfortunately the most likely if the US intervenes directly. Another option is to split the country into two or more parts. A third option is for the status quo to return as before. But whatever happens, Syria will no longer be independent and the war will last for many years. Unfortunately, there is no fairytale, the future is collapsing. The opponents of Syria have already achieved their goal.

When assessing the twelfth benchmark, for example, when a conflict is over, the various aspects of post-conflict recovery and the impact of these processes on a regional or global scale are analyzed. With a reasonable and adequate post-conflict recovery, it is possible to neutralize the threat (s) that caused the conflict.

The thirteenth benchmark outlines the risks and threats of the crisis or conflict for a given country or region, as well as the possible consequences. For example, the main consequences for Europe of the conflicts in Syria, Libya, Iraq and Afghanistan are the mass refugee wave, the transfer of radical Islam and the deployment of terrorists among the refugee wave, including the creation of "sleeping" terrorist cells. These three implications call for adequate measures to be taken by the Authorities with a view to organizing an effective response.

An analysis of the risks and threats in assessing the latest indicator shows that there are also hybrid threats of a complex and multifaceted nature. Their individual components (information, psychological, cybernetic, diplomatic, economic, military, etc.) work together and synchronously, exerting effective pressure on the opposing party.

According to some authors, the hybrid threat is defined by the crisis situation in Lebanon in 2006. It is related to the actions of the militant Shiite Hezbollah hybrid organization against the Israeli army.

As a result of the implementation of the system of indicators for assessment of crisis and conflict areas, changes and corrections in their content are possible.

The indicators for the assessment of crisis and conflict areas are important for the formulation of challenges, the associated risks and threats (including the hybrid type), these indicators should be used for training to build experts capable of analyzing and assessing crisis and conflict areas, such as the Western Balkans, the Black Sea-Caspian region, North Africa, Central and South Asia.

Hybrid conflicts (wars) have specific tools. According to NATO views, the forms of hybrid action are as follows:

1. information operations;

2. psychological operations;

3. cyber attacks;

4. an economic embargo, stopping investment, interrupting the supply of energy, blocking the flow of goods in the relations of the countries creating obstacles to achieving the objectives of "hybrid operations";

5. hidden funding of certain political entities or structures in the opposing country, a targeted influence on world markets to the detriment of certain countries, interruptions in normal wage payments and pensions in separatist regions, etc.;

6. protest actions of opposition movements, destructive actions of "agents of influence" embedded in local government structures and supporting course for self-determination of territories, etc.);

7. armed attacks and diversionary (special) actions; 
Here, the basic principles of conducting "hybrid actions" are timeliness, suddenness and concealment. The latter of these principles means that the special actions related to force measures are of a hidden nature, in which there is no pronounced external aggressor.

The complex of hybrid actions is directed to a strictly defined target site, most often a state (possibly a non-state entity), to its most vulnerable and unprotected elements, with a specific strategic goal. This results in a synergistic effect of the use of hybrid actions, with its destructive power being greater than the sum of the composite actions. This effect is particularly dangerous to the security of the target state.

Preparing to counter a variety of threats should be a daily routine for each country. It is crucial to continuously collect, share and evaluate the information received to provide and identify the intentions of triggering a hybrid scenario, which should be accompanied by specialized training and exercises to enhance the preparation for effective coping with hybrid threats.

Building and developing capabilities to identify and track emerging hybrid threats in crisis and conflict assessment will be a challenge for analysts who should give adequate assessment and suggestions for action by each country's political leadership to counteract hybrid threats.

Training, teachings and especially education play an important role in the preparation of analysts. They are tools to increase the response to hybrid attacks, therefore they should also include continuous training of the decisionmaking process and joint implementation of military and non-military response measures and extension of cooperation mechanisms with other actors in complex scenarios in and beyond a military conflict.

The complexity and ambiguity of hybrid threats requires continuous monitoring and adaptation of identification and planning processes (immediate planning and crisis response planning), a more dynamic, vigorous and adequate assessment of the emerging or emerging crisis, timely decision making that will expand opportunities to ensure an early response to a future crisis. Early analysis and assessment of a possible crisis and / or emerging conflict is a key approach to implementing adequate response measures.

Supporting action at strategic level requires early recognition of the development of the hybrid campaign, its objectives, to ensure that sufficient forces and means of effective deterrence are ensured. Therefore, high-intellectual flexibility is needed in proactive decision-making in conditions of considerable uncertainty in the system and command and control processes and operational flexibility in the deployment and use of available forces. Expanding the speed and flexibility options for proactive decision-making will allow a timely and appropriate response in identifying hybrid threats, but it is crucial to understand that a hybrid campaign can always escalate into an open military conflict.

Given the complex dependencies in the overall architecture of the capabilities themselves and the responsibilities of management in their construction and use, increasing the training of analysts should begin with the improvement of knowledge and training. The necessary expertise to assess crises and conflicts can only be created by activating the available potential on a common permanent intellectual platform. Modern training methods increasingly involve the use of training simulations, which will prepare analysts for actions in the modern information environment.

Effective training will be key to success in a rapidly changing environment. In the future, training should be available everywhere, at any time to respond to dynamic environmental changes.

In order to achieve this, in particular, the process of obtaining, analyzing and disseminating information needs to be known in detail when preparing and assessing the factors for the operation environment.

Knowledge enhancement can be used as a working mechanism to help change attitudes and a better understanding of changes in the security environment, analyzes, assessments and possible prospects for threat development that will enhance the intellectual potential of planning and implementing measures and response operations.

\section{Conclusion:-}

The possibility of strategic long-term strategic threats, as well as the need to increase the threat detection and response potential, require the transformation / diversification of analyst training, critical and creative thinking skills 
in the conduct of traditional and non-traditional military and non-military operations, mainly mixed in nature and interacting with other institutions and organizations.

Education and training play an important role in the preparation and readiness to counteract hybrid threats and hybrid conflicts, which necessarily require specialized training to implement the decision-making models of different countries.

The system of indicators for the assessment of crisis and conflict areas, as discussed in the report, is open to change and complementarity. Research into this issue will raise the scientific level of crisis management and conflictology, and will help to enhance the role of the preventive factor in the national and international security of each country.

\section{References:-}

1. Dimitrov, D., Conflictology, S., University of National and World Economy, 2004, pp. 44-45.

2. Hemdi A. Taha, Introduction to Operation Research, Williams Publishing House, Moscow, 2001.

3. Zahariev, I., Maneuvering Approach for Conducting Operations from Land Force Formations in a Complex Environment", Sofia, BA, 2015: 67-72.

4. Nikolaychuk, I. On the essence of the hybrid war in the context of the current military-political situation, M., Problems of the National Strategy, 2016 / book. 3, pp. 85-101.

5. Penev, P. Fundamentals of Crisis and Conflict Theory, S., BA, 2009.

6. Stoyanov, N. Hybrid Wars, S., East-West, 2016.

7. Vidolov, B. Current Problems arising from the Assessment of crisis and conflict areas in hybrid threats and conflicts, BA, Sofia, 2017. 